\title{
The Right Book to Help Our Ailing Society to Recover (Review)
}

\section{Roma Kriaučiuniene}

(Vilnius University, roma.kriauciuniene@uki.vu.lt)

Review of: Georg Lind (2016), How to Teach Morality. Promoting Deliberation and Discussion, Reducing Violence and Deceit, pp. 200, Berlin: Logos Verlag.

The IX edition of the Summer School entitled "Futures: Imagining the World of Tomorrow", organized by CeSPeC (Centre for Studies on Contemporary Thought), was devoted to the topic of future and its relations to the problematic present time. Among many issues addressed during the sessions of presentations delivered by $\mathrm{PhD}$ students and PostDocs, and scholars from diverse areas of research (philosophy, sociology anthropology, pedagogy, etc.) was the theme of the importance of education in strengthening our capacity to build our future. It appears that our educational systems are not capable of solving the current crises our societies face today and seem to be failing in fostering critical thinking of our learners, and in providing favourable conditions and learning environment for the development of democratic competencies of our learners that could consequently lead to the solution of many problems.

Many diverse research proposals presented at the Summer school included the analysis of moral competence that was based on Georg Lind's original tool of measurement of moral competence - Moral Competence Test (MCT). Konstanz Moral Dilemma Discussion Method (KMDD), developed by G. Lind, was also applied in Summer School sessions as a discussion method by prof. Ewa Nowak. Therefore, the review of the book by prof. Georg Lind How to Teach Morality. Promoting Deliberation and Discussion, Reducing Violence and Deceit is relevant to the context and thematic panorama of CeSPeC Summer School as well as might offer its participants and wider audience a deeper insight into moral competence. Prof. Georg Lind has written extensively on different issues of moral competence and its development, and his latest book How to Teach Morality. Promoting Deliberation and Discussion, Reducing Violence and Deceit published last year encompasses all his extensive research work and findings. The very essence of this work lies in the words of the title of the book - "moralitycan be taught", the idea that should be encouraging all educators to commit themselves to the development of moral competence of their learners, to "step outside" the realms of their subjects and to integrate moral issues in their 
classroom practices, to raise their students' awareness of moral issues, to help their students acquire skills of moral deliberation and strengthen their moral competence.

Many problems that our societies face today are global - rise of terrorism, disrespect to human existence, degradation of values and consequently of actions the fall of human values: truth speaking, nonviolence, helping others. Transformation is necessary and only education should and could help (Wood 2007, Brimi 2009, Wicks et al. 2010, Dolan 2011, Ferrero 2011). Therefore, G. Lind's book is timely - to help our ailing societies to recover and gain our moral compass to guide us in our everyday lives. As G. Lind wrote in one of his earlier works, in democratic societies people should be able to make autonomous moral decisions, based on universal moral principles. This could be achieved, as the author convincingly proves throughout his book, by the development of moral competence. G. Lind (2016) dedicated his book "to people of our one and only world", which is an inspiring call for concerted efforts of all people to make our world better and in a certain way it implies the universality of morality.

In the introductory part of the book the author prof. Georg Lind focuses on the need to foster moral competence and the role of education in this area. The author starts with an optimistic idea that "humans are dependent upon education for their morality, and they are certainly morally educable" (Lind 2015,11). The main idea that morality could be increased by education is interwoven into the whole introductory part and is the most convincing and encouraging idea for educators. As many scientists of education (Wringe 2005, Kotler 2010, Maruggi 2011, Glanzer 2012) maintain, there is a need for nurturing and fostering moral competence of our learners at different levels of education. G. Lind provides the reasons why: morality is not innate, it should be developed, however, the most important, all-embracing reason being - to curb violence, deceit and misuse of power. Teachers, professors should provide favourable conditions for their learners to foster moral competence and help learners become mature citizens of our society who will be able to make autonomous decisions based on moral principles in the future.

G. Lind introduces the way how morality could be nurtured effectively, which is by using the original tool, developed by the author himself, the KMDD method, a very powerful educational tool for honing one's moral-democratic skills and fostering moral competence. At the very beginning of the book the author discloses the essence of KMDD method, its similarities with BlattKohlberg dilemma discussion method as well as its differences, mainly - an active participation of learners in the process of discussion and providing arguments "for" and "against" the protagonists' actions.

For the sake of clarity the author also provides the definition of morality and points out its difference from ethics. The author speaks about inner internal rules that govern one's behaviour, which are the most important and reveal 
the true essence of a person. Inner rules governing a person's behaviour seem to be more empowering than the external standards that we all should abide to. Morality, according to G. Lind, is an aspect of behaviour. Actually, G. Lind speaks about two aspects of moral behaviour - moral orientations and moral competence, the latter of which can and needs to be learnt, whereas moral orientations are considered to be the basic moral ideals that most people share and the importance of which are acknowledged by all, if requested.

G. Lind proves the need to develop moral competence for everyone by providing a convincing example of KMDD application in a class of German Armed Force Officers, which only confirms the fact that morality permeates our everyday lives and that raising awareness of the need of moral reflection and deliberation in presumably strictly outlined and "clear" situations is very important.

The first chapter of the book "Democracy, morality, and education" consists of 8 sections and is devoted to showing the readers why moral competence is necessary for the democratic society, why its citizens should develop moral competence, if they want to maintain peace and democracy as well as healthy societies, and to prevent the abuse of authority.

Part 1 of the book 'Theoretical background' includes 4 chapters covering the following: the meanings and aspects of morality, the dual aspect model of moral behaviour meaning and measurement of moral competence, and the origins of morality.

In the first chapter of the theoretical part 'On the meanings and aspects of morality' the author expands the explanation of what morality means by specifying the external and internal standards of morality that a moral person should comply with. The author provides an extensive definition of moral competence and ways and means of its development. The author proves the reader that morality cannot be understood only as one's compliance with moral standards as a person's moral judgement is always needed.

The author points out limitations of the understanding of morality that is based only on the external moral rules. Although on the one hand, following rules might seem to be a very easy task, as one should act according to the set rules, however, it leaves very many unanswered questions. It might not always be clear, how a particular moral rule could be applied in one situation and then in another, what to do if there are alternatives, how to decide which option is the best. The author leads to the conclusion that moral rules are not enough as they are only "a general prescription, it cannot be applied exactly and mechanically in identical ways in each particular circumstance. It is up to a person how it applies in a given situation" (Lind 2016, 43). What is more, the author highlights the importance of the origin of the rule by drawing the readers' attention to the question of the moral capacity of the creator of the rule. 
G. Lind also discusses morality from the internal point of view, which means that human behaviour is moral if it is in compliance with the person's inner moral values and moral principles. However, the author highlights that a person's moral orientations and morally good intentions are not enough to determine moral behaviour. There is no one-to-one relationship between moral principle and behaviour. If it were, as the author claims, it would be very easy to teach children at school how to behave morally and that would be enough. However, in reality what is necessary is a person's ability of critical thought and action that could promote moral behaviour. In order to behave morally, the person has to choose between different moral orientations and in a particular contextual situation, which means that the choices are not the easy ones, these choices require a person to have moral competence.

The next section of this chapter 'Morality as competence' G. Lind extends the definition of morality by adding the notion of moral competence, which he defines as "the ability to solve problems and conflicts on the basis of universal moral principles through thinking and discussion, instead of using violence, deceit and force" (Lind 2016, 45). By providing examples from our history the author proves convincingly that moral competence is necessary for resolution of problems and conflicts in democratic societies. If there is a lack of moral competence then people try to solve their problems by force, deceit, fraud, violence, and they can even act in favour of a dictatorship. Thus, the author reiterates a way out, which is the development of moral competence. The author repeatedly expresses a very strong belief that democratization of the society depends largely on the development of citizens' moral competence, which could be achieved by good education. The author stresses the fact that we should not wait, as Kohlberg believed, until school and society are democratized somehow on their own. Moral democratic competence could be promoted by dilemma discussion method that is the most powerful and sustainable method of a person's moral development.

In the next chapter of the theoretical part 'The dual-aspect model of moral behaviour' G. Lind presents the dual aspect model of morality consisting of moral orientation (affective aspect) and moral competence (cognitive aspect) as well as provides arguments for the criticism of the model consisting of three components: affective (moral orientations), cognitive (moral competence) and behavioural. According to G. Lind (2016, 52) moral orientations and competence are not separate components they cannot be separated from behaviour or from one another. According to G. Lind, they are different aspects (properties, attributes) of one's behaviour and, as the author puts it vividly by presenting a comparison to the shape and weight of the ball, these attributes could be differentiated but could not be separated from the ball. Moral orientation is considered to be the internal force that drives and energizes the behaviour. By presenting convincing research findings the author proves that in order to learn about one's moral behaviour it is not 
enough to measure one's moral orientations as it is not indicative enough of one's moral behaviour. Evidently, most people acknowledge the same moral orientations. To prove this, the author presents research into moral orientations of university students and prisoners (Lind 2016, 54), where both groups of the respondents proved to have strikingly similar moral orientations. When it comes to teaching moral orientations, the author suggests that it is better to create favourable conditions for promotion of moral competence rather than making teaching moral orientations as the primary focus of the lesson. Furthermore, the author proves by his research results that apparently go in line with other researchers' findings (Thornberg 2008, Kotler 2010) that teachers do not know much about the moral development of children and are hardly prepared how to foster moral competence. For instance, some authors (Hadley 2001, Fenner 2006, Kunzman 2005 ) point out that there is no clear consensus on which aspects and how to integrate moral dimension into teaching/learning process; besides, teachers complain about the lack of time and expertise, and therefore avoid it as a change in students' moral attitudes is considered to be a sphere that is intimidating, obscure, and difficult to define.

In this section the author specifies that moral competence is the ability that is manifested in the actual behaviour of people. When it comes to measurement of moral behaviour the author claims that it is not enough to assess only the conscious account of respondents' behaviour without referring to one's inner processes or the unconscious layer of moral behaviour. The author presents the dual-aspect-dual-layer model of the moral self and at the end of the section (Lind 2016, 57) the author claims to aim at fostering the unconscious moral competence as well as addressing the layer of conscious ethical and psychological reflection. According to G. Lind, education must include all aspects of the self. As the author puts it: "Besides the development of our unconscious moral orientation and skills that determine our behaviour, we also need conscious thought and conscious dialogue with others, including the articulation of our moral emotions in speech and writing and the deciphering of the moral emotions and skills in others" (Lind 2016, 57).

In the third chapter of the theoretical part 'Meaning and measurement of moral competence' the author describes an innovative, new measurement methodology allowing to measure internal, structural properties of a person's behaviour: the Moral competence Test (MCT), an original measurement instrument developed and designed by the author himself. The author explains how Moral competence Test (MCT) measures a person's moral competence in a completely objective way by allowing to study moral competence in a scientific way. The explanation why classical psychometric tests are incompatible with moral philosophy is also provided.

The author also discloses how moral competence is manifested in behaviour and how it impacts social behaviour. The correlation of moral competence 
with the helping behaviour is provided as well. Based on the results of the experimental study presented in this section the author concludes that the participants with higher moral competence were more willing to help others than those with the lower moral competence, the explanation that was given was that the participants needed more time to make a decision. Experimental evidence is also provided that those with lower moral competence show higher consumption of alcohol and drugs than those with higher moral competence. Young people with higher moral competence can resolve problems and conflicts by talking and therefore do not have the need to use alcohol or drugs. According to the author: "Moral competence then seems to lower the risk of becoming drug addict when confronted with blows of fate or just with difficult situations at school or work" (Lind 2016, 82). Thus, this is really very good news for educationalists, while fostering young people's moral competence we can make them more resistant to endure difficulties in their lives and protect them from drug and alcohol abuse. Those who have lower moral competence are more likely to turn to criminal behaviour. Moreover, the author points out that criminals can be re-socialized by supporting their moral competence with the help of KMDD method.

The author also draws readers' attention to the fact that children's critical thinking abilities should be more developed at schools. This could be done by the application of more varied teaching methods, however, as the research shows teachers seem to be unwilling to lose control of their classrooms by allowing more freedom and more conflict in the classroom which they are not ready to solve. This suggests that teacher training institutions should foster moral competence of teachers and their capacity to solve conflicts in a democratic way.

The last chapter of the theoretical part answers the question: which factors determine morality: the genes, the environment or education. G. Lind denies the theory that morality can be genetically transferred that we could be born with certain inborn moral ideals. In that case, as the author puts it: "we could just sit back and watch it growing or not" (Lind 2016, 91). The author makes a conclusion that genes do not uniquely determine moral development, but the environment plays a very important role. The author refers to the assumption of moral development theory represented by Piaget, Kohlberg and Rest that a person's moral development undergoes the same pattern of sequence from bottom to top and proves that this assumption could be misleading by providing experimental data which refute the invariantly upward moral development. The moral development could stagnate and undergo regression if no education to stimulate the moral development is provided. Furthermore, the author presents the evidence that education (and not age) is the most powerful factor in moral development. Thus, the author concludes that "we must not put our hands in our laps and naively believe that morality comes with age and needs no support" (Lind 2016, 95). We should 
provide educational opportunities for people to support their moral development. This conclusion is supported by the research data that the author provides. The author states the method of moral dilemma discussion seems to be very effective. Moral skill can be taught and learnt as a result of educational processes. However, the author forewarns that insufficient instruction leads to a stagnation or fall in moral competence.

The second part of the book 'Fostering moral competence' describes the methods for promoting moral competence: the Konstanz method of moral dilemma discussion (KMDD) and Just Community methods. The KMDD is based on the Dual-Aspect-Theory of moral behaviour and development and has been proved to be effective and efficient as it has been evaluated by pre- and posttesting measurements and its reliability of fostering moral competence has been well established. The KMDD can be used in different cultures with people above the age of eight years old. However, teachers must be trained thoroughly in order to make the KMDD method really effective.

The other method that is presented in the book is Just Community method that could be applied in school communities to promote citizenship and prepare pupils to become citizens of democratic societies. Differently from KMDD method Just Community method has not yet been proved to be a powerful tool for fostering moral competence.

The second part of the book is devoted to the presentation of KMDD method, its aims, didactic principles: maximum attention and willingness to learn, triggering discussion through semi-real dilemma stories, alternating phases of support and challenge, self-moderation of the discussion, matter orientation instead of people orientation. The author presents the comparison of KMDD method with the method of Blatt-Kohlberg finishing the section by the generalization that KMDD's aim is to help participants to find the best solution for a real dilemma based on sincere moral feelings.

The following chapter of the second part of the book titled 'Preparing and implementing KMDD sessions' is devoted to the explanation how to conduct KMDD sessions in the most beneficial way. The most important message for the reader is that KMDD leads to measurable and enduring increases in moral competence among participants and to a substantial improvement of the learning climate in the rest of subject-based teaching. In the next chapter 'Measuring the efficacy of KMDD session' the author explains how the effectiveness of KMDD is assessed. Chapter 9 is devoted to the description of Just Community method with the presentation of its comparison with the KMDD, as well as the aims and didactic principles underlying this method. The next chapter overviews the experience of Just Community projects, its application in various schools and the extension of this method.

In Chapter 11 the author explains how to teach KMDD teachers. This preparation is really necessary as the author stresses the challenges that 
teachers face: they must promote their own moral competence and also learn how to promote the moral competence of others. Therefore, the teachers have to align the theory and the method, to give learners the opportunity to become aware of and articulate their own feelings, to take a back seat in order not to hinder students' learning and to deal with moral feelings of their own and others. The author describes why thorough training of teachers is necessary as well as explicates the benefits for academic teaching. One of the attendees of KMDD workshop and training conducted by the author in Konstanz in 2014, wrote:

Throughout my participation in the KMDD workshop and training conducted in Konstanz with facilitation provided by prof. Georg Lind, I found the experience to be both a valuable opportunity for personal and professional development, as expected. What I did not expect to find, though, was for my own perceived moral democratic competence to shift in deep ways. During the course, I could almost "feel" novel neural connections being made as extant pathways were stretched and nurtured to grow in new directions. In a sense, I became more aware of what I previously did not "know"; the course helped make certain lines of moral thinking and discussion visible which were previously "invisible" [...]. I look forward to keeping abreast of future KMDD-related events and publications so as to further develop and spread democratic skills and behaviours. I wish to improve my critical thinking and problem-solving ability to effectively deal with a multitude of challenging situations within my researcher-consultant role and too my interpersonal relationships. In this way, KMDD training has granted me significant entry into the realm of democratic dialogue and proved an efficacious learning opportunity. I endeavour to be an effective advocate of the method, as I believe that the KMDD, alongside similar validated experiential empathy and perspective-building education, can change our world for the better (Aiden Sisler, MEd, PhD Candidate, TU-Berlin, Fall 2014).

The last chapter of the book deals with frequently asked questions which help the reader to summarize the main points that might not be completely clear after having read the book for the first time concerning the development of moral competence, KMDD and Just Community methods as well as questions about moral psychology and education, and ethics.

Appendix includes nine phases of a KMDD session, observation sheet, documentation of a KMDD session, guidelines how to write a moral dilemma story, educative dilemma stories, glossary and bibliography.

Thus, the conclusion might be made that G. Lind's book sends a very clear message to the reader: many social problems could be solved, democratic way of life could be preserved and developed if communal consensus-building, moral reflection and deliberation skills and moral competence of members of our society were developed and fostered. 
The book is timely, articulate, convincing, inspiring, and encouraging to work for the best of our societies.

\section{Literature}

Brimi, H. 2009. Academic Instructors or Moral Guides? Moral Education in America and the Teacher's Dilemma. Clearing House, 82 (3), 125-130.

Dolan, S. L. 2011. Coaching by Values: A Guide to Success in the Life of Business and the Business of Life. Bloomington: iUniverse.

Fenner, A. 2006. Intercultural Awareness As an Integral Part of Foreign Language Learning. Coherence of Principles, Cohesion of Competences. European Centre for Modern Languages: Council of Europe Publishing, 40-59.

Ferrero, D. J. 2011. What Students Need to Learn. The Humanities: Why Such a Hard Sell?. Educational Leadership, 68 (6), 22-26, available at http://www.ascd.org/publications/educationalleadership/mar11/vol68/num06/The-Humanities@-Why-Such-aHard-Sell\%C2\%A2.aspx [accessed on February 26, 2011].

Glanzer, P. L. 2012. The Missing Factor in Higher Education. Christianity Today, 56, (3), 18-23.

Hadley, A. 2010. Teaching Language in Context. Independence (KY): Heinle \& Heinle.

Kotler, A. 2010. Education's Important Role in Social Cohesion. Education Review, 22, (2), 46-54.

Kunzman, R. 2005. Dealing with Morally Controversial Issues in the Classroom. (Faculty Shark, 2005), http://www.facultyshack.com/article.php3?idnum $=42$ [accessed on February 20, 2010].

Maruggi, M. 2011. Debating Moral Education: Rethinking the Modern University. Teaching Theology \& Religion, 14 (4), 390-392.

Thornberg, R. 2008. The Lack of Professional Knowledge in Values Education. Teaching and Teacher Education: An International Journal of Research $\begin{array}{llll}\text { and } \quad \text { Studies, } & 24 & \text { (7), }\end{array}$ http://dx.doi.org/10.1016/i.tate.2008.04.004.

Wicks, A. C., Freeman, R. E., Werhane, P. H. \& Martin, \& K. E. 2010. Business Ethics: A Managerial Approach. New Jersey: Pearson Education.

Wood, P. 2007. Homicides in Higher Education: Some Reflections on the Moral Mission of the University. Acad. Quest., 20, 277-294.

Wringe, C. 2005. Moral Education Beyond the Teaching of Right and Wrong. Dordrecht: Springer. 


\title{
Roma Kriaučiunienè \\ (Vilnius University, roma.kriauciuniene@uki.vu.lt)
}

The Right Book to Help Our Ailing Society to Recover

\begin{abstract}
This paper is a review of Georg Lind's latest book: How to Teach Morality. Promoting Deliberation and Discussion, Reducing Violence and Deceit (2016), and focuses on the main theme of the book - morality can be taught, the idea that is most encouraging for educators. Many researchers agree that our societies face many problems, such as violence, deceit, corruption, disrespect to the human nature, which on an individual level seem to stem from the lack of moral competence. Therefore, G. Lind's book is timely, providing answers to those who are concerned about our future. It will be of interest and great value not only for the participants of CeSPeC Summer School of 2016, who were trying to attain the inspiration for an immediate present-day action to reshape our future for the better, but to all of us who are committed to the enhancement of human existence and especially educators, who are engaged in the development of moral competence of their learners. This review is an attempt to prove to the readers that G. Lind's book How to Teach Morality. Promoting Deliberation and Discussion, Reducing Violence and Deceit, is the right book to help our ailing societies to recover.
\end{abstract}

Keywords: moral competence, Moral Competence Test, KMDD method, education, morality

Ethics in Progress (ISSN 2084-9257). Vol. 8 (2017). No. 1, Art. \#12, pp. 197-206.

Creative Commons BY-SA 3.0

Doi: 10.14746/eip.2017.1.12 